\title{
Low Handgrip Strength Levels in Non-Athlete Adolescents Compared to Adolescent Athletes
}

\author{
Tuba Melekoğlu ${ }^{1}$, Ali Işin ${ }^{1}$, Ayşsen Türk ${ }^{2}$ \\ ${ }^{1}$ Akdeniz University Faculty of Sport Sciences, Antalya, Turkey \\ ${ }^{2}$ University of Health Sciences Antalya Training and Research Hospital, Antalya, Turkey \\ Correspondence: Tuba Melekoğlu, Akdeniz University, Faculty of Sports Sciences, 07058, Antalya, Turkey.
}

Received: November 15, 2018

Accepted: December 21, 2018 Online Published: December 25, 2018

doi:10.11114/jets.v7i2.3908

URL: https://doi.org/10.11114/jets.v7i2.3908

\begin{abstract}
Handgrip strength is an important determinant of general health. The primary purpose of this study is to examine the handgrip strength levels in adolescents in terms of sports participation. The second purpose is to determine the association between handgrip strength and other strength parameters. Physically active adolescent athletes $(\mathrm{n}=31$, $14.26 \pm 0.68$ years), and the age, pubertal stage and gender-matched non-athlete adolescents $(\mathrm{n}=31,14.21 \pm 0.66$ years $)$ at the age of 13 to 15 participated in the study. Maximum isometric muscle strength for hand, leg, and back were measured with a handheld dynamometer. Handgrip strength was correlated with leg strength and back strength ( $\mathrm{r}=0.675$; $\mathrm{r}=0.698$, respectively). Non-athletes had lower strength values compared to the athletes $(98.48 \pm 38.25 \mathrm{~kg}$ vs $82.94 \pm$ $33.70 \mathrm{~kg} ; 91.48 \pm 35.23 \mathrm{~kg}$ vs $70.35 \pm 25.81 \mathrm{~kg} ; 30.53 \pm 7.05 \mathrm{~kg} ; 25.97 \pm 5.98 \mathrm{~kg}$ for leg, back and handgrip strength, respectively). There was a positive correlation between handgrip strength and other strength parameters in adolescents. Therefore, handgrip strength can be used as a general strength indicator in adolescents. Sports participation in adolescents seems to increase strength parameters notably and may affect health correlatively.
\end{abstract}

Keywords: handgrip strength, adolescents, athletes, back strength, leg strength

\section{Introduction}

Muscle strength, which increases during growth, is one of the most important elements of physical fitness and health. In the literature, it is stated that the muscle strength ranges obtained from healthy children may be used as a reference to interpret the acute and chronic diseases in children and adolescents (Davies, Greenwood, \& Jones, 1988; Morey, Pieper, \& Cornoni-Huntley, 1998).

Muscle strength varies depending on age and gender. Concomitant development of muscle mass and muscle fiber size, the strength of children increases throughout the maturity. Thus, muscle strength is largely associated with height and body mass (Jaric, 2002; Markovic \& Jaric, 2004). Regarding gender, muscle mass may be higher in boys than in girls because of their height and body mass advantage. The underlying reason for this case might be the hormonal differences such as increased testosterone in adolescent males. Therefore, higher muscle mass might lead to higher muscle strength. Another reason for gender-related differences, particularly during adolescence, may be the changes in the body due to increased total fat percentage of girls. There is also a slight decrease in muscle strength after puberty. It has been reported that males are stronger than girls in all age categories, especially after puberty (Wind, Takken, Helders, \& Engelbert, 2010).

It is known that strength increases with age and increasing lean muscle mass. It has been reported that the muscle fiber composition and ATP-phosphocreatine concentration are similar to those of adults since 6-8 of age, and age-related increases in handgrip strength (HGS) have been reported to be related to increased muscle mass (Luisa, Micheletti Cremasco, Torre Antonio, Alberto, \& Roberto, 2016; Sartorio, Lafortuna, Pogliaghi, \& Trecate, 2002).

The methods used to measure muscle strength are similar in adults and children. However, in cases where muscle coordination is not fully developed in children and adolescents, there is a risk of injury during strength measurement for large muscle groups. In addition, since it is time consuming to obtain data on the strength measurement of all muscle groups, it is necessary to develop lower-risk and more practical measurement methods which are representative of general strength. Handgrip strength measurements have been reported in the literature as a method that can be easily 
applied and as an indicator of general strength (Davies et al., 1988; Wang, Leger, \& Dumas, 2005).

Handgrip strength is an important component directly affecting performance in several sports such as rock climbing, handball, judo, weightlifting and racket sports. In related literature, HGS is used to evaluate the general strength (Pizzigalli, Micheletti Cremasco, La Torre, Rainoldi, \& Benis, 2015). To our knowledge, HGS is reported as an indicator of general strength in adult studies, yet a similar study in adolescents has not been found. In this study, it is aimed to investigate the relationship between leg, back and handgrip strength, which are most preferred methods in strength measurements. Another aim is to assess the relationship between strength parameters and a number of variables such as age, height, body mass and participation in sport.

\section{Material and Methods}

\subsection{Experimental Approach to the Problem}

To investigate the relationship among age, anthropometrical variables, sports participation and strength variables 31 athletes and 31 non-athletes between the ages of 13 and 15 were evaluated. In this study, relationship between leg, back and handgrip strength which are mostly used methods in strength measurements was investigated. Volunteers' height, body mass, body fat percentages, body mass index (BMI), handgrip strength (HGS), leg strength (LS) and back strength (BS) were measured. The study was approved by the Akdeniz University, Clinical Research Ethics Committee (494-11.07.2018) and it was conducted in accordance with the Declaration of Helsinki.

\subsection{Participants}

Thirty-one physically active adolescents $(\mathrm{n}=31 ; 14.26 \pm 0.68$ years; 16 males and 15 females) who participated sports trainings (football, handball, swimming, athletics) regularly for at least 3 years, between the ages of 13 and 15 years volunteered to participate in the study. As the control group; the age and gender matched sedentary adolescents $(n=31$; $14.21 \pm 0.66$ years) were recruited study. All participants were healthy and free of any history of musculoskeletal disorders. Prior to the measurements, participants were informed about the test protocols, and informed consent was obtained from participating adolescents and their parents. The physical characteristics of the participants in the study are shown in Table 1.

\subsection{Anthropometric Measurements}

The height of participants was measured using a stadiometer with $0.1 \mathrm{~cm}$ of precision (SECA 213, Germany). Body mass index (BMI) was calculated by dividing body mass in kilograms by the square of height in meters (Gerver \& Bruin, 1996). Body weight and body fat percentages were measured using a bioelectrical impedance device (Tanita SC 330, Japan). Prior to bioelectrical impedance measurements, all participants were instructed to comply with the following bioelectrical impedance guidelines: a) no eating and drinking for at least 4 hours prior to measurement b) no excessive exercise participation in the last 12 hours c) no alcohol consumption for 12 hours prior to measurement d) if possible, urinating in the last 30 minutes e) no diuretics for the last 7 days (Heyward \& Wagner, 2004).

\subsection{Strength Measurements}

All subjects were tested for maximal isometric strength with respect to handgrip, leg and back strength by using handheld Takei dynamometer.

\subsubsection{Handgrip Strength (HGS)}

A digital hand dynamometer (Takei A5401, Japan) with adjustable grip handle, which weights 5.0-100.0 kg and 0.1 of precision, was used. For each participant, this dynamometer was adjusted according to the size of the participant's hand. Participants were asked to perform three trials and the best score was used for statistical analysis in the study (Johnson \& Nelson, 1969).

\subsubsection{Leg Strength (LS) and Back Strength (BS) Measurements}

The maximal isometric strength values of the legs and back were determined using a $1 \mathrm{~kg}$ sensitivity dynamometer (Takei A5402, Japan). Participants, wearing trainers, stood on the foot plate of the dynamometer with the scapulae and buttocks positioned flat against the wall. Participants flexed their legs in the angle of $135^{\circ}$. The pull bar of the dynamometer was placed in the hands and the chain length was adjusted properly. Participants were asked to extend the legs with maximal effort by pulling the bar simultaneously without jerking. The best score after three trials was used for statistical analysis in the study (Johnson \& Nelson, 1969).

For the back-strength measurements, participants were positioned in the same way as in the leg strength measurement, but with the legs straight and the back flexed from hip with fully extended elbows, until the tips of the index fingers reached the patellae. The pull bar of the dynamometer was placed in the hands and the chain length was adjusted. The highest score of three pulls was recorded. Participants were given a 3-5 min rest between each attempt to ensure full recovery. 


\subsection{Data Analysis}

Skewness, kurtosis (Tabachnick \& Fidell, 2007), histogram, quantile-quantile plots (QQ-plots), Shapiro-Wilk test (Shapiro \& Wilk, 1965) and Levene test (Martin \& Bridgmon, 2012) revealed no variable violated normality and homogeneity of variance assumptions. In this study, following statistical tests were applied; Independent Sample T-Test to evaluate the difference between the groups and Pearson Correlation test to examine the correlation of the data. Statistical significance was set at $\mathrm{p}<0.05$. SPSS 24 package program was used to analyse data.

\section{Results}

The physical characteristics of the participants are shown in Table 1.

Table 1. Physical Characteristics

\begin{tabular}{lcccc}
\hline Variables & $\begin{array}{c}\text { Athletes }(\mathbf{n}=\mathbf{3 1}) \\
\mathbf{M}( \pm \mathbf{S D})\end{array}$ & $\begin{array}{c}\text { Non-Athletes }(\mathbf{n}=\mathbf{3 1}) \\
\mathbf{M} \pm \mathbf{S D}\end{array}$ & $\mathbf{t}$ & $\mathbf{p}$ \\
\hline Age (years) & $14.26 \pm 0.69$ & $14.21 \pm 0.98$ & 0.248 & 0.805 \\
Body height $(\mathbf{c m})$ & $163.48 \pm 7.55$ & $160.16 \pm 9.52$ & 1.522 & 0.133 \\
Body mass $(\mathbf{k g})$ & $53.86 \pm 6.70$ & $51.31 \pm 10.60$ & 1.133 & 0.262 \\
BMI $\left(\mathbf{k g} / \mathbf{m}^{2}\right)$ & $20.14 \pm 2.16$ & $19.80 \pm 2.64$ & 0.549 & 0.585 \\
Fat \% $(\%)$ & $14.73 \pm 7.09$ & $14.15 \pm 8.13$ & 0.295 & 0.769 \\
\hline
\end{tabular}

BMI: Body mass index, Fat\%: Body fat percentage, M \pm SD: Mean \pm Standard deviation

As a result of matching physical characteristics between athletes and non-athletes, there were no statistical differences between groups $(\mathrm{p}>0.05)$.

Table 2. Descriptive statistics of handgrip, back and leg strength

\begin{tabular}{lcccc}
\hline Variables & Athletes $(\mathbf{n}=\mathbf{3 1})$ & Non-Athletes $(\mathbf{n}=\mathbf{3 1})$ & $\mathbf{t}$ & $\mathbf{p}$ \\
& $\mathbf{M} \pm \mathbf{S D}$ & $\mathbf{M} \pm \mathbf{S D}$ & & \\
\hline LS $\mathbf{( k g )}$ & $98.48 \pm 38.25$ & $82.94 \pm 33.70$ & 1.698 & 0.095 \\
BS $(\mathbf{k g})$ & $91.48 \pm 35.23$ & $70.35 \pm 25.81$ & 2.706 & 0.009 \\
HGS $(\mathbf{k g})$ & $30.53 \pm 7.05$ & $25.97 \pm 5.98$ & 2.745 & 0.008
\end{tabular}

LS: Leg strength, BS: Back strength, HGS: Handgrip strength, $\mathbf{M} \pm$ SD: Mean \pm Standard deviation

BS and HGS values of athletes were significantly higher than those of non-athletes $(p<0.01)$, although LS differences between groups were not statistically significant ( $p>0.05)$.

Table 3. The relationship of anthropometric characteristics and strength values

\begin{tabular}{lllllllll}
\hline & Age & Height & B. Mass & BMI & Fat $\%$ & LS & BS & HGS \\
\hline Age & 1 & & & & & & & \\
Height & $.329 * *$ & 1 & & & & & & \\
B. Mass & .207 & $.748 * * *$ & 1 & & & & & \\
BMI & -.001 & .208 & $.798^{* * *}$ & 1 & & & & \\
Fat \% & .022 & .052 & $.510^{* * *}$ & $.725^{* * *}$ & 1 & & \\
LS & .016 & $.536^{* * *}$ & $.405^{* *}$ & .088 & $-.316^{* *}$ & 1 & & \\
BS & .080 & $.585^{* * *}$ & $.484 * * *$ & .169 & $-.236^{*}$ & $.897^{* * *}$ & 1 & \\
HGS & .017 & $.570^{* * *}$ & $.564 * * *$ & $.323^{* *}$ & .065 & $.675^{* * *}$ & $.698^{* * *}$ & 1 \\
\hline
\end{tabular}

B. Mass: Body mass, BMI: Body mass index, Fat\%: Body fat percentage, LS: Leg strength, BS: Back strength, HGS: Handgrip strength, Pearson's coefficient of correlation ( $r) * p<0.05 ; * * \mathrm{p}<0.01 ; * * * \mathrm{p}<0.001$.

There was a positive correlation between handgrip strength and leg strength $(\mathrm{r}=0.675)$, leg strength and back strength $(\mathrm{r}=0.897)$ and handgrip strength and back strength $(\mathrm{r}=0.698)$. This correlation among leg, back and handgrip strength values was found to be statistically significant $(\mathrm{p}<0.001)$. Moreover, a positive correlation between leg, back, handgrip strength and body height and body mass was noted $(\mathrm{p}<0.01, \mathrm{p}<0.001)$. 


\section{Discussion}

In this study, it is aimed to investigate the relationship between leg, back and handgrip strength, and to determine whether grip strength is a predictor for total muscle strength in adolescents. Secondly, it is aimed to assess the relationship between strength parameters and a number of variables such as age, height, body mass and participation in sport. Sixty-two athletes and non-athletes between the ages of 13 and 15 years participated in this study. The physical characteristics of the athletes and non- athletes were similar ( $p>0.05)$.

Strength is considered as an important determinant for health-related life quality. Therefore, most of the rehabilitation programs focus on strength development as a protective factor for health. As an indicator of health, the strength assessment methods are important for clinical and applied sciences (Peterson, Saltarelli, Visich, \& Gordon, 2014). Although there are various strength assessment methods, it has been reported that the HGS can provide an easy and a proxy measure of total strength. Therefore, some researchers have studied to develop grip strength cut-points for muscle and bone health. Saint-Maurice et al. (Saint-Maurice et al., 2018) reported high correlation between bone mineral content and handgrip strength, and revealed that handgrip strength cut-points for "high risk for chronic diseases, mortality and bone fracture, later in life" was $<25.7$ and $<21.2 \mathrm{~kg}$ for males and females at the age of 14 , respectively.

Reliable muscle strength measurement of different muscle groups is time-consuming. A quick and simple measurement can be a good indicator of general muscle strength. There are studies suggesting that handgrip strength may be a sufficient measure for general muscle strength in adults as it is associated with arm, back and leg strength (Davies et al., 1988; Fricke \& Schoenau, 2005), but on the individual level it is stated that this application may give misleading results. Furthermore, some studies have reported that a significant relationship between handgrip strength and physical fitness or health status (Bohannon, 2008a; da Silveira, 2005; Kerr et al., 2006). Therefore, the grip strength can be used as a quick scan for patients and groups. However, for a detailed evaluation of an individual patient, it is recommended to test several muscle groups (Wind et al., 2010). Bohannon et al. (Bohannon, 2008b) reported there was insufficient evidence to see whether grip strength is a good determiner for general muscle strength. However, as a result of our study, there was a positive correlation between handgrip strength, leg and back strength in adolescents and it is thought that grip strength could be used as a general strength indicator in adolescents.

In our study, the mean HGS for our participants was $30.53 \pm 7.05 \mathrm{~kg}$ and $25.97 \pm 5.98 \mathrm{~kg}$ for athletes and non-athletes, respectively. The results of the HGS measurements were comparable with previous studies. Considering the stated cut-points from the study of Saint-Maurice et al.(Saint-Maurice et al., 2018), the non-athletes were found to be on the edge of high risk ranges. Similarly, Cohen et al. (Cohen, López-Jaramillo, Fernández-Santos, Castro-Piñero, \& Sandercock, 2017) also reported a mean HGS as $23.9 \mathrm{~kg}$ for schoolchildren of 10-16 years of age. Conversely, Pizzigalli et al. (2015) reported that the handgrip strength of the athlete group for 13-14 years were $32.8 \pm 4.2 \mathrm{~kg}$ for the right hand and $31.5 \pm 6.0 \mathrm{~kg}$ for the left hand. The dominant handgrip strength of the athletes for the age of 13 years was $29.09 \pm 8.41 \mathrm{~kg}$ and the 14-15 age group had $42.27 \pm 7.96 \mathrm{~kg}$. (Visnapuu \& Jürimae, 2007). In agreement with other studies (Gürsoy, Akarsu, \& Hazar, 2017; Işın, Özus, \& Melekoğlu, 2018; Luisa et al., 2016; Melekoglu, 2015), we found that athletes have higher strength values compared to non-athletes.

Previous researches reported that handgrip strength highly correlated with total muscle strength (Peterson, Zhang, Saltarelli, Visich, \& Gordon, 2016; Wind et al., 2010). Similarly, according to our results, a positive correlation was noted between handgrip strength and leg strength ( $\mathrm{r}=0.675, \mathrm{p}<0.001)$, and handgrip strength and back strength ( $\mathrm{r}=0.698$, $\mathrm{p}<0.001)$. Furthermore, there was a significant correlation between LS, BS and HGS with body height and body mass. Our results suggest that handgrip strength may be a predictor of total muscle strength. There are several studies concerning the correlation between HGS, BS, and LS in adults. Kaya et al. (2018) reported a high correlation between HGS and LS ( $r=0.863$, p <0.001). Koley et al. (2010) found a statistically significant correlation between LS and BS in male cricketers $(\mathrm{p}<0.05)$. In the same study, there was no correlation between LS and BS with height, body mass and BMI values, though. Conversely, Schmidt and Toews (1970) reported that handgrip strength is related to some anthropometric characteristics such as body weight and body mass. As a result of another study on adolescent cricketers; none of the anthropometric variables other than age, height, body mass and BMI values were found to be significantly correlated with HGS. While body mass and BS were found to be correlated with each other $(r=0.453, p<0.05)$, no correlation was found between HGS and BS (Singla \& Hussain, 2018). Wang et al. (2005) examined the relationship between HGS, BS and quadriceps strength in healthy women, and found a correlation between HGS and BS ( $\mathrm{r}=0.501)$, and HGS and quadriceps strength $(\mathrm{r}=0.536)$. Further, researches revealed considerable evidence for an inverse correlation between cardio-metabolic risk factors and handgrip strength (Peterson et al., 2016; Wind et al., 2010). Even if there are controversial results about anthropometrical variables and strength, a considerable amount of studies suggested a positive association between hang grip strength as a determinant of muscular fitness and general health.

Our study revealed that athletes had higher strength values than non-athletes. Sports participation in adolescents seems 
to increase strength parameters notably, and may affect health correlatively. Based on the relationship between handgrip, back and leg strength, it is considered that the grip strength is an indicator of general health in adolescents as well as an indicator of general strength. The handgrip strength of non-athletes was found to be on the edge of the high-risk ranges for general health. Sports participation in adolescent seems to increase strength parameters notably, and may affect health correlatively. Therefore, contents of physical education lessons and their frequency, and also additional sports participation is important to enhance adolescents' health. Future research is needed to determine the handgrip strength cut-points by considering age, ethnicity, gender, sports participation and health status. As an indicator of general health status, determining the handgrip strength cut-points by considering age, ethnicity, gender, sports participation and health status is very important to interpret public health. Additional sports participation is required to enhance adolescents' strength parameters, and correlatively their health status.

A major limitation of this study was the relatively small sample size. Further studies with a larger sample size which is inclusive of different sports branches and age groups is recommended to interpret the relationship of sports participation and handgrip strength.

\section{References}

Bohannon, R. W. (2008a). Hand-grip dynamometry predicts future outcomes in aging adults. J Geriatr Phys Ther, 3l(1), 3-10. https://doi.org/10.1519/00139143-200831010-00002

Bohannon, R. W. (2008b). Is it legitimate to characterize muscle strength using a limited number of measures? $J$ Strength Cond Res, 22(1), 166-173. https://doi.org/10.1519/JSC.0b013e31815f993d

Cohen, D., López-Jaramillo, P., Fernández-Santos, J., Castro-Piñero, J., \& Sandercock, G. (2017). Muscle strength is associated with lower diastolic blood pressure in schoolchildren. Prev Med, 95, 1-6.

https://doi.org/10.1016/j.ypmed.2016.11.006

da Silveira, T. R. (2005). Comparison between handgrip strength, subjective global assessment, and prognostic nutritional index in assessing malnutrition and predicting clinical outcome in cirrhotic outpatients. Nutrition, 21(2), 113-117. https://doi.org/10.1016/j.nut.2004.02.002

Davies, B., Greenwood, E. J., \& Jones, S. (1988). Gender difference in the relationship of performance in the handgrip and standing long jump tests to lean limb volume in young adults. Eur J Appl Physiol Occup Physiol, 58(3), 315-320. https://doi.org/10.1007/BF00417269

Fricke, O., \& Schoenau, E. (2005). Examining the developing skeletal muscle: Why, what and how? J Musculoskelet Neuronal Interact, 5(3), 225.

Gerver, W. J. M., \& Bruin, R. (1996). Paediatric morphometrics: a reference manual. Utrecht: Universitaire Pers Maastricht

Gürsoy, R., Akarsu, S., \& Hazar, K. (2017). Examination of correlation among reaction time, strength, and flexibility of sedentary and athletes in different branches J Hum Sci., 14(4), 3282-3291.

Heyward, V. H., \& Wagner, D. R. (2004). Applied body composition assessment. USA: Human Kinetics.

Işın, A., Özus, Ç. B. Ö., \& Melekoğlu, T. (2018). 13-14 Yaş arası adölesanlarda el boyutları ile el kavrama kuvveti ilişkisi Sportif Bakış: Spor ve Eğitim Bilimleri Dergisi, 5(1), 9-19.

Jaric, S. (2002). Muscle strength testing. Sports Med, 32(10), 615-631. https://doi.org/10.2165/00007256-200232100-00002

Johnson, B. L., \& Nelson, J. K. (1969). Practical measurements for evaluation in physical education. USA: Macmillan Pub Co.

Kaya, M., Soyal, M., \& Karakuş, M. (2018). The effect of the leg and back strength of the serve and tennis players to the serve throwing speed and agility. Physical Educ Student, 22(5), 237-242. https://doi.org/10.15561/20755279.2018.0502

Kerr, A., Syddall, H., Cooper, C., Turner, G., Briggs, R., \& Sayer, A. A. (2006). Does admission grip strength predict length of stay in hospitalised older patients? Age Ageing, 35(1), 82-84. https://doi.org/10.1093/ageing/afj010

Koley, S., Khajuria, A., \& Melton, S. (2010). The correlation between back strength and leg strength among Indian inter-university male cricketers. Facta Univ Phys Educ Sport, 8(2), 125-132.

Luisa, P., Micheletti Cremasco, M., Torre Antonio, L., Alberto, R., \& Roberto, B. (2016). Hand grip strength and anthropometric characteristics in Italian female national basketball teams. J Sports Med Phys Fitness, 1-6. 
Markovic, G., \& Jaric, S. (2004). Movement performance and body size: the relationship for different groups of tests. Eur J Appl Physiol, 92(1-2), 139-149. https://doi.org/10.1007/s00421-004-1076-7

Martin, W. E., \& Bridgmon, K. D. (2012). Quantitative and statistical research methods: From hypothesis to results (Vol. 42): John Wiley \& Sons.

Melekoglu, T. (2015). The effects of sports participation in strength parameters in primary school students. Procedia-Soc Behav Sci, 186, 1013-1018. https://doi.org/10.1016/j.sbspro.2015.04.124

Morey, M. C., Pieper, C. F., \& Cornoni-Huntley, J. (1998). Physical fitness and functional limitations in community-dwelling older adults. Med Sci Sports Exerc, 30(5), 715-723. https://doi.org/10.1097/00005768-199805000-00012

Peterson, M. D., Saltarelli, W. A., Visich, P. S., \& Gordon, P. M. (2014). Strength capacity and cardiometabolic risk clustering in adolescents. Pediatrics, peds. 2013-3169. https://doi.org/10.1542/peds.2013-3169

Peterson, M. D., Zhang, P., Saltarelli, W. A., Visich, P. S., \& Gordon, P. M. (2016). Low muscle strength thresholds for the detection of cardiometabolic risk in adolescents. Am J Prev Med, 50(5), 593-599. https://doi.org/10.1016/j.amepre.2015.09.019

Pizzigalli, L., Micheletti Cremasco, M., La Torre, A., Rainoldi, A., \& Benis, R. (2015). Hand grip strength and anthropometric characteristics in Italian female National basketball teams. Sport Sci Health, 11(1), S33-S33.

Saint-Maurice, P. F., Laurson, K., Welk, G. J., Eisenmann, J., Gracia-Marco, L., Artero, E. G., ... Vicente-Rodriguez, G. (2018). Grip strength cutpoints for youth based on a clinically relevant bone health outcome. Arch Osteoporos, 13(1), 92. https://doi.org/10.1007/s11657-018-0502-0

Sartorio, A., Lafortuna, C. L., Pogliaghi, S., \& Trecate, L. (2002). The impact of gender, body dimension and body composition on hand-grip strength in healthy children. $J$ Endocrinol Invest, 25(5), 431-435. https://doi.org/10.1007/BF03344033

Schmidt, R. T., \& Toews, J. (1970). Grip strength as measured by the Jamar dynamometer. Arch Phys Med Rehabil, $51(6), 321$.

Shapiro, S. S., \& Wilk, M. B. (1965). An analysis of variance test for normality (complete samples). Biometrika, 52(3/4), 591-611.

Singla, D., \& Hussain, M. E. (2018). Association between handgrip strength and back strength in adolescent and adult cricket players. Int J Adolesc Med Health. https://doi.org/10.1515/ijamh-2017-0177

Tabachnick, B. G., \& Fidell, L. S. (2007). Using multivariate statistics: Allyn \& Bacon/Pearson Education.

Visnapuu, M., \& Jürimae, T. (2007). Handgrip strength and hand dimensions in young handball and basketball players. Journal of strength and conditioning research, 21(3), 923.

Wang, M., Leger, A., \& Dumas, G. (2005). Prediction of back strength using anthropometric and strength measurements in healthy females. Clin Biomech, 20(7), 685-692. https://doi.org/10.1016/j.clinbiomech.2005.03.003

Wind, A. E., Takken, T., Helders, P. J., \& Engelbert, R. H. (2010). Is grip strength a predictor for total muscle strength in healthy children, adolescents, and young adults? Eur J Pediatr, 169(3), 281-287. https://doi.org/10.1007/s00431-009-1010-4

\section{Copyrights}

Copyright for this article is retained by the author(s), with first publication rights granted to the journal.

This is an open-access article distributed under the terms and conditions of the Creative Commons Attribution license which permits unrestricted use, distribution, and reproduction in any medium, provided the original work is properly cited. 